\title{
Season influences FSH concentration in ovariectomized Ile-de-France ewes
}

\author{
G. W. Montgomery*, G. B. Martin†, M. R. Blanc and J. Pelletier \\ INRA, Station de Physiologie de la Reproduction, 37380 Monnaie, France
}

\begin{abstract}
Summary. Ile-de-France ewes were ovariectomized during anoestrus or the mid-luteal phase of an oestrous cycle (day of ovariectomy = Day 0). In a short-term study, FSH concentrations were measured in blood samples collected hourly the day before and on Days 1, 3, 7 and 15 after ovariectomy (10 ewes per group). FSH concentrations increased significantly from $6 \cdot 1$ to $16.5 \mathrm{ng} / \mathrm{ml}$ within 1 day of ovariectomy and increased further to $47 \cdot 1 \mathrm{ng} / \mathrm{ml}$ by Day 15 . Differences between seasons of ovariectomy were not significant.

In a long-term study, FSH concentrations were measured in blood samples collected hourly on Days 7, 15, 30, 60, 90, 120,150 and 180 after ovariectomy in anoestrus or the breeding season ( 10 ewes per group). Further samples were taken ( 5 ewes/group) at 240 and 365 days after ovariectomy. The pattern of change in FSH after ovariectomy differed between the two seasons and the interaction between season and sampling day was significant. For ewes ovariectomized during anoestrus, FSH concentrations increased to a maximum by Day 180 and remained high thereafter. In contrast FSH increased more slowly in ewes ovariectomized in the breeding season and differences between the groups were significant from Day 90 to Day 270 . However, both groups had similar FSH concentrations at Day 365.

These results show that FSH concentrations increase rapidly after ovariectomy. There are seasonal differences in FSH concentrations in the absence of ovarian feedback with increases in FSH concentration around the time of the onset of the breeding season. Once FSH concentrations had reached a maximum, major seasonal changes were no longer apparent.
\end{abstract}

\section{Introduction}

Photoperiod is the principal factor determining the length and timing of the breeding season in ewes (for review see Karsch et al., 1984). Acting through the pineal gland, photoperiod determines the activity of the LH pulse generating mechanism. Seasonal changes occur both in the ability of oestradiol to inhibit the frequency of LH pulses (Legan et al., 1977; Goodman et al., 1982; Martin et al., 1983) and direct effects on the frequency of LH pulses in the absence of gonadal steroids (Karsch et al., 1980; Goodman et al., 1982; Montgomery et al., 1985; Robinson et al., 1985).

LH is coupled with pulsatile GnRH release from the hypothalamus (Levine et al., 1982; Clarke \& Cummins, 1982) and exogenous GnRH pulses influence FSH concentrations in ewes (Clarke $e t$ al., 1984). Therefore, direct effects of photoperiod on the pulse generator would be expected to influence both the frequency of LH pulses and the plasma concentrations of FSH. Indeed, in castrated Soay rams, FSH concentrations vary with alternating short and long days (Lincoln \& Short, 1980).

\footnotetext{
${ }^{*}$ Present address: Invermay Agricultural Centre, Private Bag, Mosgiel, New Zealand.

†Present address: School of Agriculture (Animal Science), University of WA, Nedlands, Western Australia 6009, Australia.
} 
The aims of the present experiments were to study short-term and long-term changes in FSH concentrations in ewes after ovariectomy during anoestrus or during the mid-luteal phase of a cycle during the breeding season.

\section{Materials and Methods}

Ile-de-France ewes were housed in groups in a light-proof building and subjected to normal seasonal changes in daylength regulated by electric clocks. Each morning the ewes were fed a diet of $300 \mathrm{~g}$ lucerne pellets, $400 \mathrm{~g}$ wheat and $30 \mathrm{~g}$ mineral supplement, with wheat straw ad libitum. The ewes were ovariectomized during anoestrus or early in the breeding season as described in detail by Montgomery et al. (1985). To measure the responses to ovariectomy, blood was sampled every $10 \mathrm{~min}$ for $6 \mathrm{~h}$ on all occasions, except the day before ovariectomy in the short-term study (see below) when samples were taken every $20 \mathrm{~min}$ for $12 \mathrm{~h}$. All of these samples were assayed for $\mathbf{L H}$ and the results of this study have been reported previously (Montgomery et al., 1985). For the present study we measured FSH in all samples from several animals, up to 15 days after ovariectomy. However, analyses of these data revealed no clear evidence of pulsatile release of FSH and that no extra information was gained from the measurement of more than hourly samples. We therefore measured FSH in hourly samples selected from those taken more frequently.

Short-term study. Groups of 10 ewes were ovariectomized early in the breeding season (22 October) or in anoestrus (23 March). Concentrations of FSH were measured in samples collected the day before ovariectomy and on Days 1, 3, 7 and 15 after ovariectomy (day of ovariectomy $=$ Day 0 ). Samples were centrifuged and plasma stored at $-14^{\circ} \mathrm{C}$ until assay.

Long-term study. Further groups of 10 ewes were ovariectomized during anoestrus (17 March) or early in the breeding season (29 September). Concentrations of FSH were measured in samples collected the day before ovariectomy (day of ovariectomy = Day 0), on Days 7, 15,30 and then at about 30-day intervals until Day 180 (6 months) after ovariectomy. After Day 180, 5 ewes were removed from each group and the remaining 5 ewes were sampled on Day 270 (9 months) and Day 365 (12 months) after ovariectomy. Samples were centrifuged and plasma stored at $-14^{\circ} \mathrm{C}$ until assay.

FSH assay. FSH concentrations were measured in duplicate by an homologous radioimmunoassay using CNRSFSH-P26 (equiv. to $14 \times$ NIH-FSH-S3) as standard and HG-FSH-225-226 (equiv. to $36 \times \mathrm{NIH-FSH-S3)} \mathrm{as} \mathrm{labelled}$ tracer (Blanc \& Poirier, 1979). Cross-reactions with other pituitary hormones were small (TSH 1-2\%; all others $\leqslant 0.02 \%$ ). Sensitivity of the assay was $2 \mathrm{ng} / \mathrm{ml}$. The intra-assay coefficient of variation was $<12 \%$ at a value of B/Bo of $75-15 \%$. The inter-assay coefficient of variation was $<20 \%$ at a value of $\mathrm{B} / \mathrm{Bo}$ of $35 \%$.

Data analyses. Concentrations of FSH in the short-term and long-term studies were analysed by nested analyses of variance with season of ovariectomy as the main plot, day of sampling as the sub-plot and hourly samples as sub-sub-plots. Results are given with standard errors of differences (s.e.d.) or standard errors of means (s.e.m.). Significant differences refer to values of $P<0.05$ unless otherwise stated.

\section{Results}

\section{Short-term study}

The mean concentration of FSH in ewes during the mid-luteal phase of the oestrous cycle was $5.3 \mathrm{ng} / \mathrm{ml}$ and did not differ significantly from the concentration of $6.8 \mathrm{ng} / \mathrm{ml}$ in ewes during anoestrus (s.e.d. $=5 \cdot 4$ ). After ovariectomy in both groups, FSH concentrations increased rapidly and within 1 day they were more than double the concentrations recorded before ovariectomy $(P<0.001$, Fig. 1). Concentrations doubled again by Day 3 and reached a mean concentration of $47 \mathrm{ng} / \mathrm{ml}$ by Day 15 . Differences in the concentrations of $\mathrm{FSH}$ amongst ewes ovariectomized in the breeding season or mid-anoestrus were small and non-significant (s.e.d. $=4 \cdot 3$ ).

\section{Long-term study}

The mean concentration of FSH was the same for ewes in the mid-luteal phase of the oestrous cycle $(4.5 \mathrm{ng} / \mathrm{ml})$ and during mid-anoestrus $(4.5 \mathrm{ng} / \mathrm{ml}$, s.e.d. $=3.9)$. FSH concentrations increased rapidly after ovariectomy to reach $25.6 \mathrm{ng} / \mathrm{ml}$ by Day 7 after ovariectomy (Fig. 2). The initial increase in FSH concentration was similar for ewes in both seasons of ovariectomy and FSH concentrations did not differ significantly between the groups at Day 7 or Day 15 after ovariectomy. 


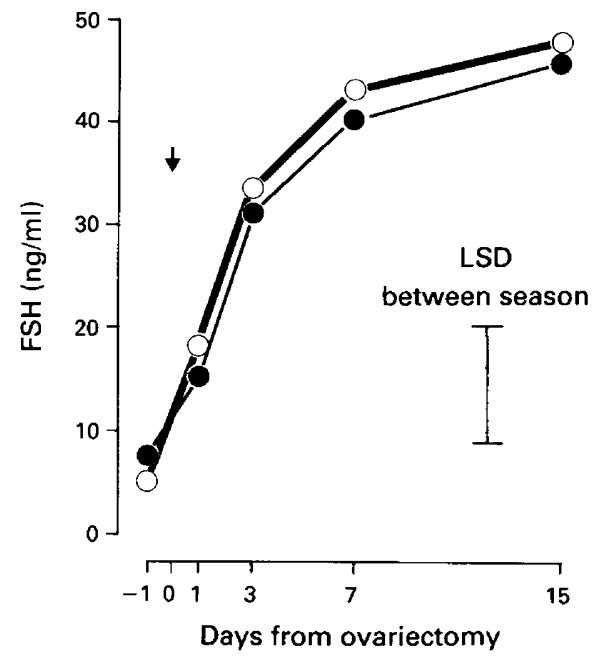

Fig. 1. Short-term changes in FSH concentrations in ewes ovariectomized (arrow) during anoestrus $(\mathrm{N}=10,0)$ or the mid-luteal phase of an oestrous cycle $(\mathbf{N}=10,0)$.

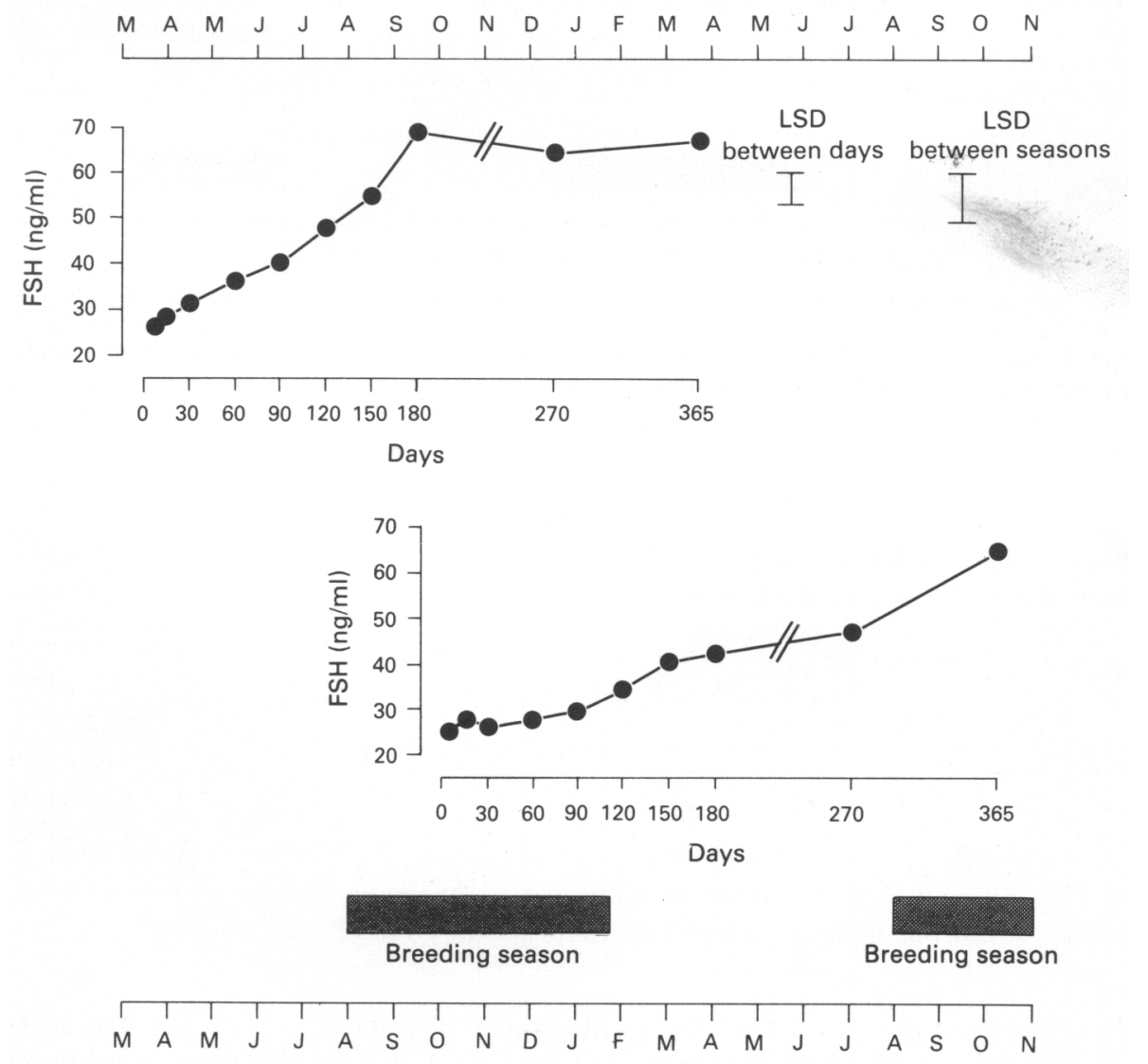

Fig. 2. Long-term changes in FSH concentrations in ewes ovariectomized during anoestrus (March) or the mid-luteal phase of an oestrous cycle (September). In each group results to 180 days after ovariectomy are means of 10 ewes and subsequent results are means of 5 ewes. Data for the breeding season in Ile-de-France ewes are taken from Thimonier \& Mauléon (1969). 

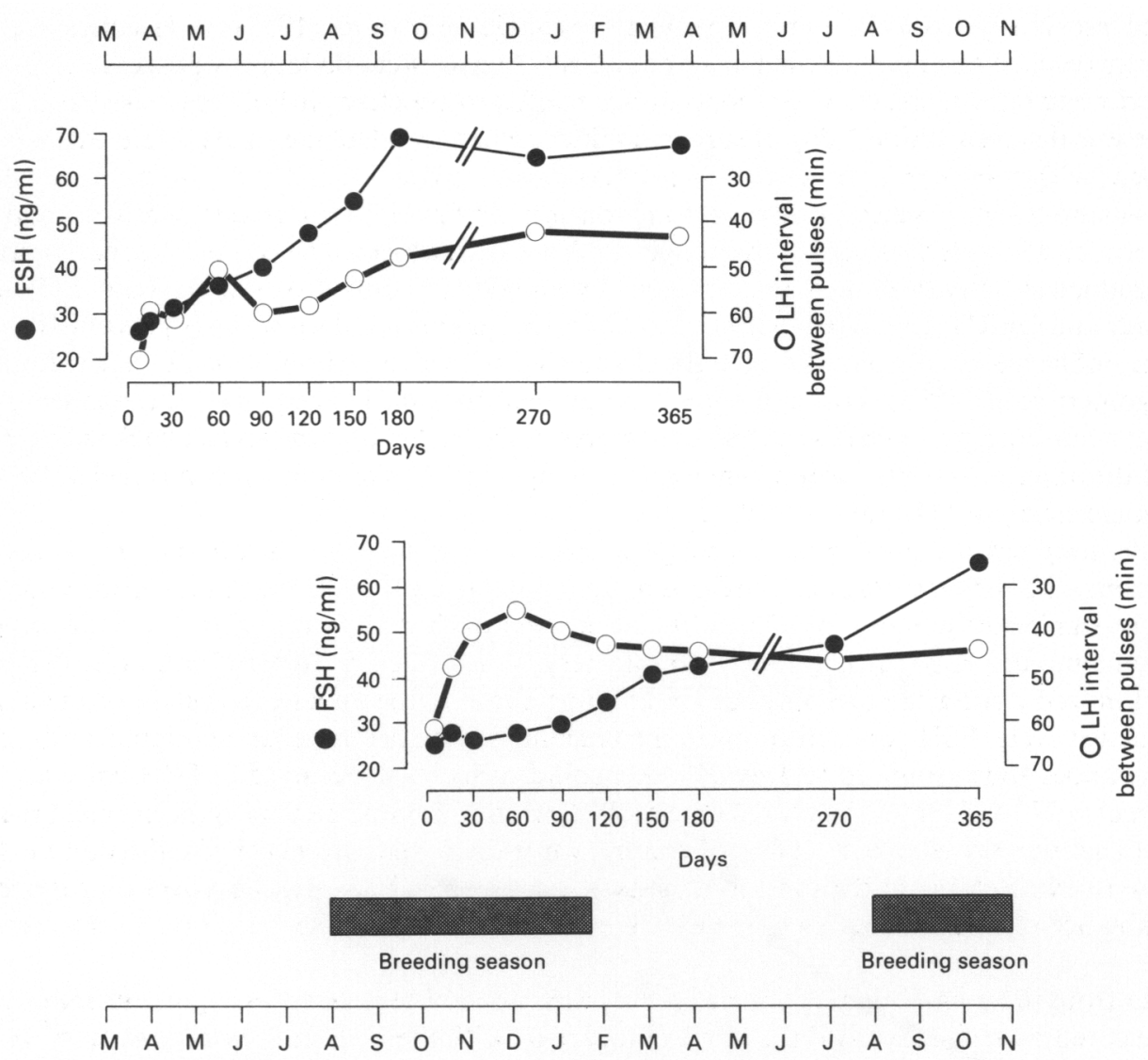

Fig. 3. Long-term changes in FSH concentrations and LH pulse frequency in ewes ovariectomized during anoestrus (March) or the mid-luteal phase of the oestrous cycle (September). Data on LH pulse frequency are redrawn from Montgomery et al. (1985), inverting the scale for interpulse interval so that changes in frequency match the change in the plotted data.

Subsequently the pattern of increase in FSH concentrations differed markedly for the two groups (Fig. 2) and the interaction between season of ovariectomy and sampling day on FSH concentrations was significant $(P<0 \cdot 01)$. For ewes ovariectomized during anoestrus, FSH concentrations increased progressively to reach a maximum concentration at Day 180 after ovariectomy. The concentrations of FSH at Day 270 and Day 365 did not differ significantly from the concentration at Day 180.

In contrast, FSH concentrations increased more slowly in ewes ovariectomized in the breeding season. The difference between the groups was almost significant at Day $90(29.6$ and $39.7 \mathrm{ng} / \mathrm{ml}$, s.e.d. $=5 \cdot 2,0 \cdot 1>P>0.05$ ). From Day 120 to Day 270 , FSH concentrations were significantly lower in ewes ovariectomized during the breeding season. FSH concentrations then increased between Day 270 and Day 365 in the breeding season group so that by Day 365 , the difference between the groups was no longer significant $(64 \cdot 8$ and $67 \cdot 7 \mathrm{ng} / \mathrm{ml}$, s.e.d. $=5 \cdot 2)$.

\section{Discussion}

These results show that patterns of change in FSH concentration were markedly different after ovariectomy in anoestrus or during the mid-luteal phase of a cycle in the breeding season. Furthermore, the timing of increases in FSH concentration differed from increases in LH pulse frequency 
reported previously from the same experiment (Montgomery et al., 1985). FSH concentrations eventually reached a maximum when major seasonal changes were no longer apparent.

There was a rapid increase in FSH concentrations after ovariectomy in both seasons. A significant increase was detected within 1 day of surgery and concentrations had increased 4-fold by Day 3 , in agreement with results from other breeds of sheep (Lahlou-Kassi et al., 1984; Webb et al., 1985). There was no effect of season of ovariectomy during the first 15 days as assessed from both the short-term and long-term studies. This might not have been expected since the influence of season on reproductive activity is mediated through hypothalamic control of GnRH (and LH) pulse frequency and GnRH is involved in the control of FSH secretion. Indeed we have previously shown that the influence of season on LH pulse frequency is evident within 1 week of ovariectomy (Montgomery et al., 1985). This difference between the FSH and LH responses is explained by the fact that acute changes in FSH secretion are primarily controlled by ovarian feedback acting at the level of the anterior pituitary gland, while acute changes in LH secretion are controlled at the level of the hypothalamus (Martin et al., 1986).

In the long term, the patterns of change in FSH were quite different for the two seasons of ovariectomy. FSH concentrations increased more rapidly in ewes ovariectomized during anoestrus and were significantly higher by Day 120 as they approached the time of the normal breeding season (Thimonier \& Mauléon, 1969; Montgomery et al., 1985) compared with ewes that were ovariectomized during the breeding season and just entering the anoestrous phase of the annual reproductive cycle. FSH concentrations in the breeding season group remained significantly lower than the anoestrous group up to Day 270. A significant increase occurred in FSH concentration between Day 270 and Day 365 over the time of the transition from anoestrus to the normal breeding season (Thimonier \& Mauléon, 1969). Therefore, while there were no effects of season on the FSH response to ovariectomy in the short term, season did influence FSH secretion over longer periods in the absence of ovarian feedback, increasing it before and during the transition to the breeding season.

Data from the long-term experiment on the frequency of LH pulses (Montgomery et al., 1985) have been redrawn and included for direct comparison with the FSH concentrations (Fig. 3). The timing of increases in FSH concentration and LH pulse frequency are different for both seasons of ovariectomy. In ewes ovariectomized in anoestrus, FSH concentrations increased before a detectable increase in LH pulse frequency at the onset of the normal breeding season. In contrast, ovariectomy early in the breeding season did not lead to major changes in FSH concentrations despite a striking increase in LH pulse frequency. One explanation for the different timing of these changes in FSH concentration and LH pulse frequency is that FSH concentrations are highest at intermediate GnRH pulse frequencies. Studies with exogenous GnRH pulses in sheep and monkeys support this view. In sexually quiescent Soay rams, exogenous GnRH pulses at one pulse every $3.4 \mathrm{~h}$ increased the FSH concentrations (Lincoln \& Short, 1980). In other studies in sheep, a reduction in the frequency of exogenous GnRH pulses from one every hour to one every 2 or $4 \mathrm{~h}$ also increased FSH concentrations (Clarke et al., 1984). Similarly, in female rhesus monkeys, exogenous GnRH pulses every $2 \mathrm{~h}$ resulted in higher FSH concentrations than did pulses every hour or every $3 \mathrm{~h}$ (Pohl et al., 1983). Wildt et al. (1981) suggested that the increase in FSH concentration that resulted from a reduction in pulses to once every $3 \mathrm{~h}$ was due to an increase in the releasable pools of pituitary FSH and LH since there was also an increase in the amplitude of LH pulses. The longer interval between pulses offset the increase in LH pulse amplitude by allowing more time for the clearance of $\mathrm{LH}$. The FSH releasable pool may have increased to a greater extent and since FSH has a longer half life, concentrations of FSH increased with the less frequent GnRH pulses.

For the intact animal, this relationship between GnRH pulse frequency and FSH secretion would have important consequences for the series of events leading to the onset of the breeding season. There would be a significant increase in FSH secretion, before LH secretion was maximal, which would play a major role in the initial stages of gonadal redevelopment. In the Soay ram the sequence of events takes this form (Lincoln, 1978). 
In the ewes ovariectomized in September the change from short days to long days at the end of the breeding season did not induce a decrease in the concentrations of FSH. This contrasts with observations by Lincoln \& Short (1980) of the effects of photoperiod on the castrated Soay ram. The differences between the observations could be explained by the more profound seasonal changes in reproductive activity characteristic of the Soay breed. In ewes ovariectomized during anoestrus, maximum FSH concentrations were reached at Day 180 in the first 2 months of the normal breeding season. Subsequently, FSH concentrations did not change significantly when measured at the end of the breeding season or in the following anoestrous period. In ewes ovariectomized during the breeding season, maximum concentrations were not attained until during the time of the second breeding season ( 1 year, after ovariectomy). The concentration of FSH at that time was similar to the maximum FSH concentrations in the anoestrous group. These data provide support for the absence of seasonal changes in LH pulse frequency in long-term ovariectomized ewes (Montgomery et al., 1985; Fig. 3) and extend the finding to suggest that sensitivity to seasonal changes is reduced for both gonadotrophins.

Seasonal changes in LH pulse frequency in long-term ovariectomized ewes were observed in a study of ewes kept outdoors under natural light (Robinson et al., 1985). After the initial increase during the autumn, pulse frequency decreased significantly. However, it did not decline to the minimum value observed during the first summer. The ewes in our study were housed indoors under artificial lighting and fed a constant plane of nutrition. Ewe liveweight did not change with season as might be expected with ewes kept outdoors. A low plane of nutrition can advance the end of the breeding season (Allison \& Kelly, 1979) and inhibit the activity of the LH pulse generator (Foster et al., 1986). Any seasonal changes in nutrition in ewes kept outdoors may have influenced the activity of the pulse generator and contribute to the seasonal differences observed by Robinson et al. (1985), but not in the present experiment.

We thank Alain Locatelli, Jean-Claude Poirier, Marie-Odile Moulin, Didier Chesneau and Claude Cornu for technical assistance. G.W.M. was supported by a New Zealand Public Service Study Award and a Bourse de Stage, and G.B.M. by an Overseas Study Award from the Australian Meat Research Council.

\section{References}

Allison, A.J. \& Kelly, R.W. (1979) Effects of differential nutrition on the incidence of oestrus and ovulation rate in Booroola $\times$ Romney and Romney ewes. Proc. N.Z. Soc. Anim. Prod. 39, 43-49.

Blanc, M.R. \& Poirier, J.C. (1979) A new homologous radioimmunoassay for ovine follicle stimulating hormone: development and characterization. Annls Biol. anim. Biochim. Biophys. 19, 1011-1026.

Clarke, I.J. \& Cummins, J.T. (1982) The temporal relationship between gonadotropin releasing hormone $(\mathrm{GnRH})$ and luteinizing hormone ( $\mathrm{LH})$ secretion in ovariectomized ewes. Endocrinology 111, 1737-1739.

Clarke, I.J., Cummins, J.T., Findlay, J.K., Burman, K.J. \& Doughton, B. (1984) Effects on plasma luteinizing hormone and follicle-stimulating hormone of varying the frequency and amplitude of gonadotropinreleasing hormone pulses in ovariectomized ewes with hypothalamo-pituitary disconnection. Neuroendocrinology 39, 214-221.

Foster, D.L., Karsch, F.J., Olster, D.H., Ryan, K.D. \& Yellon, S.M. (1986) Determinants of puberty in a seasonal breeder. Recent Prog. Horm. Res. 42, 331-378.
Goodman, R.L., Bittman, E.L., Foster, D.L. \& Karsch, F.J. (1982) Alterations in the control of luteinizing hormone pulse frequency underlie the seasonal variation in estradiol negative feedback in the ewe. Biol. Reprod. 27, 580-589.

Karsch, F.J., Goodman, R.L. \& Legan, S.J. (1980) Feedback basis of seasonal breeding: test of an hypothesis. J. Reprod. Fert. 58, 521-535.

Karsch, F.J., Bittman, E.L., Foster, D.L., Goodman, R.L., Legan, S.J. \& Robinson, J.E. (1984) Neuroendocrine basis of seasonal reproduction. Recent Prog. Horm. Res. 40, 185-225.

Lahlou-Kassi, A., Schams, D. \& Glatzel, P. (1984) Plasma gonadotrophin concentration during the oestrous cycle and after ovariectomy in two breeds of sheep with low and high fecundity. J. Reprod. Fert. 70, $165-173$.

Legan, S.J., Karsch, F.J. \& Foster, D.L. (1977) The endocrine control of seasonal reproductive function in the ewe: a marked change in response to the negative feedback action of estradiol on luteinizing hormone secretion. Endocrinology 101, 818-824.

Levine, J.E., Pau, K.-Y.F., Ramirez, V.D. \& Jackson, 
G.L. (1982) Simultaneous measurement of luteinizing hormone-releasing hormone and luteinizing hormone release in unanesthetized, ovariectomized sheep. Endocrinology 111, 1449-1455.

Lincoln, G.A. (1978) The temporal relationship between plasma levels of FSH and LH in the ram. J. Reprod. Fert. 53, 31-37.

Lincoln, G.A. \& Short, R.V. (1980) Seasonal breeding: Nature's contraceptive. Recent Prog. Horm. Res. 36, 143.

Martin, G.B., Scaramuzzi, R.J. \& Henstridge, J.D. (1983) Effects of oestradiol, progesterone and androstenedione on the pulsatile secretion of luteinizing hormone in ovariectomized ewes during spring and autumn. J. Endocr. 96, 181-193.

Martin, G.B., Wallace, J.M., Taylor, P.L., Fraser, H.M., Tsonis, C.G. \& McNeilly, A.S. (1986) The roles of inhibin and gonadotrophin releasing hormone in the control of goandotrophin secretion in the ewe. $J$. Endocr. 111, 287-296.

Montgomery, G.W., Martin, G.B. \& Pelletier, J. (1985) Changes in pulsatile LH secretion after ovariectomy in Ile-de-Fance ewes in two seasons. J. Reprod. Fert. $73,173-183$
Pohl, C.R., Richardson, D.W., Hutchinson, J.S. Germak, J.A. \& Knobil, E. (1983) Hypophysiotropic signal frequency and the functioning of the pituitary-ovarian system in the rhesus monkey. Endocrinology 112, 2076-2080.

Robinson, J.E., Radford, H.M. \& Karsch, F.J. (1985) Seasonal changes in pulsatile luteinizing hormone (LH) secretion in the ewe: relationship of frequency of LH pulses to day length and response to estradiol negative feedback. Biol. Reprod. 33, 324-334.

Thimonier, J. \& Mauléon, P. (1969) Variations saisonnieres du comportement d'oestrus et des activites ovarienne et hypophysaire chez les ovins. Annls Biol. anim. Biochim. Biophys. 9, 233-250.

Webb, R. Baxter, G., Preece, R.D., Land, R.B. \& Springbett, A.J. (1985) Control of gonadotrophin release in Scottish Blackface and Finnish Landrace ewes during seasonal anoestrus. J. Reprod. Fert. 73, 369-378.

Wildt, L., Hausler, A., Marshall, G., Hutchinson, J.S., Plant, T.M., Belchetz, P.E. \& Knobil, E. (1981) Frequency and amplitude of gonadotrophin-releasing hormone stimulation and gonadotropin secretion in the rhesus monkey. Endocrinology 190, 376-385.

Received 26 September 1986 